\section{Reconviction rates of drug dependent patients treated in a residential therapeutic community: 10 year follow up}

A 10 year follow up study of criminal records and reconvictions of 61 drug dependent patients treated at the Ley Community, Oxford, is reported.

\section{Patients, methods, and results}

The Ley Community is a therapeutic community with facilities for residential treatment of 30-40 young people. Previous studies of the patients reported on here showed that they were mainly ! oung unmarried men and women who had left school early and had been taking various drugs for over three years. ${ }^{12}$ Most had a history of regular injections of opiates and several criminal convictions. Middle class backgrounds, an unstable work history coupled with underachievement, average intelligence, and personality characteristics associated with delinquency were common features. ${ }^{2}$

The 61 people admitted from 1971 to 1973 were followed up and divided into three groups: short stay (under one month), medium stay (under six months), and long stay (over six months). These groups were compared on admission with regard to demographic characteristics, history of criminality, and history of drug use and did not differ significantly. ${ }^{1}$ Ten years after discharge a search was made of the records of each subject in the Criminal Records Office, Scotland Yard, and the presence of subjects on general practitioners' lists and any deaths were noted through the National Health Service central register.

Sixty of the 61 people were traced. Fifty one were on a general practitioner's list, two were in prison, one was in Australia, and six were dead. The long stay group had significantly fewer convictions after discharge than before $(p<0.001)$, even when convictions precipitating admission were excluded (table). Only three of the 20 long stay patients had been reconvicted, whereas 32 of the remaining 41 patients had been cunvicted $\left(\chi^{2}=19 \cdot 35, n<0 \cdot 001\right)$. Of the six patients who had died, four (short stay group) had died as a result of drugs, one (medium stay group) had died of natural causes, and one (long stay group) had committed suicide unrelated to drugs.

\section{Comment}

Drug addicts are notoriously difficult to treat, and the associated criminality is even more resistant to treatment. Gordon found that $83 \%$ of a sample of patients who presented to a London drug clinic were convicted during 10 years of follow up and a high rate of conviction persisted even after they had given up drugs. ${ }^{3}$ Similarly, Weipert et al found that clinic treatment had no effect on the future crime rate and that during treatment the proportion of drug offences actually increased. 4

The proportion of our subjects who were reconvicted during 10 years' follow up $(57 \%)$ contrasts considerably with these findings. Our relatively low conviction rate is clearly largely accounted for by the remarkably low reconviction rate in the long stay group (15\%). The reconviction rates in the medium stay group $(70 \%)$ and short stay group $(85 \%)$ are typical of rates in other studies. Can the success of the long stay group be attributed to their treatment? This group, though highly self selected, did not differ from the others in criminal history, drug abuse, personality, intelligence, or demographic factors, which argues strongly in favour of a treatment effect resulting from a long period of residence in the therapeutic community.
The methodological pitfalls in evaluating treatment programmes for drug addiction are numerous and were discussed by Wilson. ${ }^{5}$ In particular, the willingness of people to stay in the unit may be related to the fact that they are less likely to reoffend anyway. Nevertheless, evidence suggests that those who stay for over six months show a significant reduction in personality disturbance. ${ }^{2}$ The low conviction rate in the long stay group reported after two years ${ }^{35}$ was maintained for 10 years, which is undeniably impressive.

Therapeutic communities remain a promising-perhaps the most promising - treatment option for addicts willing to submit to a substantial period of residence. They deserve more attention from researchers and policy makers.

1 Wilson S, Mandelbrote BM. The relationship between duration of treatment in herapeutic community for drug abusers and subsequent criminality. $\mathrm{Br} f$ Psychiatry 1978;132.487-91

ennard D, Wilson $\mathrm{S}$. The modification of personality disturbance in a therapeutic community for drug abusers. Br f Med Psychol 1979;52:215-21.

Drugs and delinquency: a ten year follow-up of drug clinic patients. Br F Psychiatry 1973;142:21-6.

Weipert et al. Delinquency by opiate addicts treated at two London clinics. Br $\mathcal{F}$ Psychiatry 1979;134:14-24.

5 Wilson S. Can drug abuse treatment be adequately evaluated? Acta Psychiatr Scand [Suppl] 1980;284:52-7, 62 .

(Accepted 19 April 1985)

Oxford Regional Drug Dependence Service and Littlemore Hospital, Oxford OX4 4XN

STEPHEN WILSON, MSC, FRCPSYCH, consultant psychiatrist and clinical lecturer

BERTRAM MANDELBROTE, MA, FRCPSYCH, consultant psychiatrist and clinical lecturer

Correspondence to: Dr Mandelbrote.

\section{Aminoglutethimide (with hydrocortisone) induced agranulocytosis in primary breast cancer}

Aminoglutethimide, an inhibitor of steroid synthesis, is effective for patients with endocrine sensitive breast cancer. ${ }^{1}$ Although its use has been associated with bone marrow dysfunction, ${ }^{2-4}$ it has not been possible to distinguish between a direct toxic effect of the drug versus progressive metastases or other drug treatment in patients with disseminated disease.

We are undertaking a clinical trial of adjuvant aminoglutethimide (with hydrocortisone $20 \mathrm{mg}$ twice daily) versus placebo for postmenopausal patients with primary breast cancer. Patients are randomised to receive oral aminoglutethimide within six weeks of primary treatment at a dose of $250 \mathrm{mg}$ twice daily, increasing to three times a day and then four times a day at monthly intervals. Of 161 patients who received adjuvant aminoglutethimide, three developed agranucytosis. All three patients had primary infiltrative ductal carcinoma with histological spread to axillary nodes treated by wide excision or mastectomy followed by postoperative radiotherapy to the breast or chest wall and local lymph nodes. All three patients were receiving

\begin{tabular}{|c|c|c|c|c|c|c|c|c|c|}
\hline \multirow[b]{2}{*}{ Before treatment } & & & \\
\hline & Convicted & $\begin{array}{c}\text { Not } \\
\text { convicted }\end{array}$ & Total & Convicted & $\begin{array}{c}\text { Not } \\
\text { convicted }\end{array}$ & Total & Convicted & $\begin{array}{c}\text { Not } \\
\text { convicted }\end{array}$ & Total \\
\hline $\begin{array}{l}\text { Convicted } \\
\text { Not convicted }\end{array}$ & $\begin{array}{c}16^{*} \\
2\end{array}$ & $\frac{1}{2 \dagger}$ & $\begin{array}{r}17 \\
4\end{array}$ & 14 & $\begin{array}{l}5 \\
1\end{array}$ & $\begin{array}{r}19 \\
1\end{array}$ & 3 & $\begin{array}{r}14 \\
3\end{array}$ & $\begin{array}{r}17 \\
3\end{array}$ \\
\hline Total & $18^{*}$ & 3 & 21 & $14 \ddagger$ & 6 & 20 & 3 & $17 \ddagger$ & 20 \\
\hline $\begin{array}{l}\text { McNemar test corrected for continuity } \\
\text { Probability }\end{array}$ & & $\begin{array}{l}0.00 \\
\text { NS }\end{array}$ & & & NS $(<0 \cdot 10)$ & & & $\begin{array}{c}12 \cdot 1 \\
<0.001\end{array}$ & \\
\hline
\end{tabular}

